\title{
Fluoride varnishes containing calcium glycerophosphate: fluoride uptake and the effect on in vitro enamel erosion
}

\author{
Thiago S. Carvalho • Marcelo Bönecker • \\ Markus J. Altenburger • Marília A. R. Buzalaf • \\ Fabio C. Sampaio • Adrian Lussi
}

Received: 5 February 2014 / Accepted: 13 November 2014 /Published online: 23 November 2014

(C) Springer-Verlag Berlin Heidelberg 2014

\begin{abstract}
Objectives Calcium glycerophosphate (CaGP) was added to fluoride varnishes to analyze their preventive effect on initial enamel erosion and fluoride uptake: potassium hydroxide $(\mathrm{KOH})$-soluble and $\mathrm{KOH}$-insoluble fluoride bound to enamel. Materials and methods This study was carried out in two parts. Part 1: 108 enamel samples were randomly distributed into six varnish groups: base varnish (no active ingredients); Duraphat $^{\circledR}(2.26 \% \mathrm{NaF})$; Duofluorid ${ }^{\circledR}\left(5.63 \% \mathrm{NaF} / \mathrm{CaF}_{2}\right)$; experimental varnish $1\left(1 \% \mathrm{CaGP} / 5.63 \% \mathrm{NaF} / \mathrm{CaF}_{2}\right)$; experimental varnish $2\left(5 \% \mathrm{CaGP} / 5.63 \% \mathrm{NaF} / \mathrm{CaF}_{2}\right)$; and no varnish. Cyclic demineralization ( $90 \mathrm{~s}$; citric acid, $\mathrm{pH}=3.6$ ) and remineralization $(4 \mathrm{~h})$ was made once a day, for 3 days. Change in surface microhardness (SMH) was measured. Part
\end{abstract}

T. S. Carvalho $(\square) \cdot$ A. Lussi

Department of Preventive, Restorative and Pediatric Dentistry,

University of Bern, Freiburgstrasse 7, 3010 Bern, Switzerland

e-mail: thiago.saads@zmk.unibe.ch

T. S. Carvalho $\cdot$ M. Bönecker

Department of Pediatric Dentistry, School of Dentistry, University of São Paulo, Av. Lineu Prestes, 2227, Butantã, São Paulo,

SP 05508-900, Brazil

\section{J. Altenburger}

Department of Operative Dentistry and Periodontology, University

Hospital and Dental School, University of Freiburg, Hugstetter Str.

55, 79106 Freiburg, Germany

M. A. R. Buzalaf

Department of Biological Sciences, Bauru School of Dentistry,

University of São Paulo, Al. Octávio Pinheiro Brisola, 9-75, Vila

Unversitária, Caixa Postal 73, Bauru, SP 17012-901, Brazil

\section{F. C. Sampaio}

Health Science Center, Federal University of Paraíba, Laboratório de Biologia Bucal, Castelo Branco, 58051900 João Pessoa, PB, Brazil
2: 60 enamel samples were cut in half and received no varnish (control) or a layer of varnish: Duraphat ${ }^{\circledR}$, Duofluorid ${ }^{\circledR}$, experimental varnishes 1 and 2 . Then, $\mathrm{KOH}$-soluble and $\mathrm{KOH}-$ insoluble fluoride were analyzed using an electrode.

Results After cyclic demineralization, SMH decreased in all samples, but Duraphat ${ }^{\circledR}$ caused less hardness loss. No difference was observed between varnishes containing $\mathrm{CaGP}$ and the other varnishes. Similar amounts of $\mathrm{KOH}$-soluble and insoluble fluoride was found in experimental varnish 1 and Duofluorid ${ }^{\circledR}$, while lower values were found for experimental varnish 2 and Duraphat ${ }^{\circledR}$.

Conclusion The addition of CaGP to fluoride varnishes did not increase fluoride bound to enamel and did not enhance their protection against initial enamel erosion.

Clinical relevance We observe that the fluoride varnishes containing CaGP do not promote greater amounts of fluoride bound to enamel and that fluoride bound to enamel may not be closely related to erosion prevention.

Keywords Topical fluorides · Calcium glycerophosphate Enamel $\cdot$ Dental erosion $\cdot$ Fluoride varnish $\cdot$ Tooth demineralization

\section{Introduction}

In addition to protection against caries, dentifrices $[1,2]$ and mouthwash solutions [3] have also shown protective effects dental erosion. However, this preventive effect of fluoride seems to be more effective when high fluoride concentrations are used $[4,5]$. Fluoride varnishes have high fluoride concentrations, and their adherence to the surface of the enamel can provide more time to form calcium fluoride-like $\left(\mathrm{CaF}_{2}\right.$-like $)$ material $[6,7]$. The $\mathrm{CaF}_{2}$-like material is loosely bound to the 
enamel and is analyzed in the laboratory by its solubility in potassium hydroxide $(\mathrm{KOH})$. Therefore, henceforth, it is referred to $\mathrm{KOH}$-soluble fluoride. Fluoride can also be present within the enamel crystals, which is firmly bound and insoluble in $\mathrm{KOH}$ (henceforth referred to $\mathrm{KOH}$-insoluble fluoride) [8]. During erosive challenges, $\mathrm{KOH}$-soluble fluoride serves as an additional mineral barrier preventing the direct contact of the acid with the dental enamel $[9,10]$.

Calcium glycerophosphate (CaGP) has been shown to protect enamel from cariogenic demineralization [11-13], as it interacts with hydroxylapatite increasing its resistance towards demineralization [14]. It has also been suggested that it may have a cumulative effect together with fluoride [15]. When added to fluoride varnishes, CaGP promotes fluoride release [16], and this may also increase enamel protection towards acid demineralization. So, the aims of this study were (1) to analyze the effect fluoride varnishes containing CaGP on initial enamel erosion and (2) to determine the amount of $\mathrm{KOH}$-soluble and insoluble fluoride on enamel after application of these varnishes.

\section{Materials and methods}

Fluoride varnishes and their $\mathrm{pH}$ values

Five varnishes were used:

(i) Base varnish (no active ingredients); FGM, Joinville, Brazil

(ii) $\operatorname{Duraphat}^{\circledR}\left(2.26 \% \mathrm{~F}^{-}\right.$as $\left.\mathrm{NaF}\right)$; Colgate-Palmolive $\mathrm{GmbH}$, Hamburg, Germany

(iii) Duofluorid $^{\circledR}\left(2.71 \% \mathrm{~F}^{-}\right.$as $\mathrm{NaF}$ and $2.92 \% \mathrm{~F}^{-}$as $\mathrm{CaF}_{2}$ [total $5.63 \% \mathrm{~F}^{-}$]); FGM, Joinville, Brazil

(iv) Experimental varnish $1\left(1 \% \mathrm{CaGP}\right.$ and $\left.5.63 \% \mathrm{~F}^{-}\right)$; FGM, Joinville, Brazil

(v) Experimental varnish $2\left(5 \% \mathrm{CaGP}\right.$ and $\left.5.63 \% \mathrm{~F}^{-}\right)$; FGM, Joinville, Brazil

The base varnish, Duofluorid ${ }^{\circledR}$, and experimental varnishes 1 and 2 were provided by the same manufacturer and had the same synthetic resin composition.

Since $\mathrm{pH}$ is a measure of hydrogen ion activity in aqueous solutions [17], the varnishes were mixed with water (1 part varnish to 1 part deionized water), and the solution was placed on a $\mathrm{pH}$ meter. The $\mathrm{pH}$ values obtained were 7.91 for the base varnish, 6.02 for Duraphat ${ }^{\circledR}, 7.70$ for Duofluorid ${ }^{\circledR}, 8.59$ for experimental varnish 1 , and 9.58 for experimental varnish 2 .

Sample preparation

A total of 168 caries-free permanent human molars were selected. Patients were informed about the use of their teeth for research purposes, and consent was obtained. The teeth were cut, and 168 buccal enamel surfaces were divided into two groups: 108 and 60 samples.

The 108 enamel samples were used to determine the effect of the varnishes on erosion ("Part 1-preventive effect of the varnishes on initial enamel erosion"). They were individually embedded in acrylic resin (Paladur, Heraeus Kulzer GmbH, Hanau, Germany), ground, and polished until a layer of $200 \mu \mathrm{m}$ of enamel was removed and flat smooth surfaces obtained. These enamel samples were then divided into the six groups $(n=18)$.

The other 60 samples were used to determine the amount of $\mathrm{KOH}$-soluble and insoluble fluoride on enamel ("Part 2KOH-soluble and insoluble fluoride on enamel"). Each enamel surface was cut in half, and two enamel slabs ( $a$ and $b$ ) were obtained from each buccal surface. These slabs were sequentially ground and polished to obtain a flat, smooth surface.

Part 1-preventive effect of the varnishes on initial enamel erosion

\section{Measurement of enamel softening}

Surface microhardness (SMH) was measured with six indentations made with a Knoop hardness diamond (load of $50 \mathrm{~g}$, dwell time of 15 s; MHT-10 hardness tester, Antoon Paar, Paar Physica, Graz, Austria). The SMH value was calculated from the six indentations. Enamel SMH was measured initially $\left(\mathrm{SMH}_{\mathrm{A}}\right)$, after the first enamel demineralization $\left(\mathrm{SMH}_{\mathrm{B}}\right)$, after varnish application $\left(\mathrm{SMH}_{\mathrm{C}}\right)$, and after the second $\left(\mathrm{SMH}_{\mathrm{D}}\right)$ and third $\left(\mathrm{SMH}_{\mathrm{E}}\right)$ enamel demineralization. The differences between enamel microhardness after different experimental steps, as well as the total microhardness loss, were calculated and used for statistical data analyses and interpretation.

\section{Initial enamel erosion and fluoride varnish application}

The samples were individually submitted to an erosive challenge for enamel demineralization $(90 \mathrm{~s} ; 50 \mathrm{ml}$ of $0.65 \%$ citric acid; $\mathrm{pH}=3.6 ; 25{ }^{\circ} \mathrm{C}$; in a shaking water bath at $70 \mathrm{rpm}$ ) once a day, for a total of 3 days. After the first erosive challenge, the samples received a layer of one of the varnishes according to the following groups: group 1 -base varnish, group 2-Duraphat ${ }^{\circledR}$, group 3Duofluorid $^{\circledR}$, group 4-experimental varnish 1, group 5-experimental varnish 2 , and group 6-control group with no varnish application.

A piece of $10 \times 10-\mathrm{mm}$ plastic, containing a circular window $(\varnothing=2.5 \mathrm{~mm})$, was fixed on top of each enamel surface, and $0.025 \mathrm{~g}$ of the varnish was placed on the window containing the exposed enamel. 
The samples were then incubated in the remineralizing solution $\left(4 \mathrm{~h} ; 2.2 \mathrm{ml} /\right.$ enamel block; $30^{\circ} \mathrm{C}$; in a shaking water bath at $70 \mathrm{rpm}$ ), consisting of a 1:1 mixture of artificial saliva $\left(0.213 \mathrm{~g} / 1 \mathrm{CaCl}_{2} \cdot 2 \mathrm{H}_{2} \mathrm{O} ; 0.738 \mathrm{~g} / 1 \mathrm{KH}_{2} \mathrm{PO}_{4} ; 0.381 \mathrm{~g} / 1 \mathrm{NaCl}\right.$; $1.114 \mathrm{~g} / \mathrm{K} \mathrm{KCl}$ ) and stimulated human saliva [18]. The stimulated human saliva was collected in chilled vials, from 30 healthy individuals, $2 \mathrm{~h}$ after their last meal or oral hygiene. The saliva was pooled, centrifuged for $20 \mathrm{~min}$ at $4{ }^{\circ} \mathrm{C}$ $(3000 \times g)$ and then stored at $-80^{\circ} \mathrm{C}$. The saliva was thawed in a $30^{\circ} \mathrm{C}$ water bath before being added to the artificial saliva. The remineralizing solution was prepared daily.

After the 4-h period in the remineralizing solution, the enamel blocks were rinsed in deionized water for $20 \mathrm{~s}$, and the varnish was removed using an organic solvent and a scalpel blade taking care not to touch the enamel surface.

Varnish was only applied on the first day of the cycle. During the other 2 days of the experiment, the samples were submitted to the erosive challenge $(90 \mathrm{~s})$ and the remineralizing solution (4 h), after which, an SMH measurement was carried out.

Images of the enamel surfaces were taken at the end of the experiment, at $\times 50$ magnification, using an optical microscope with an attached camera (UHL technische Mikroskopie GmbH \& Co. KG, Aßlar, Germany).

\section{Statistical analyses}

The difference between enamel hardness values after the different experimental stages was used for statistical data analysis. As the data were not normally distributed, nonparametric ANOVA model [19] with post hoc Kruskal-Wallis, Wilcoxon signed rank, and Wilcoxon rank sum tests were used with Bonferroni-Holm adjustment $(\alpha=0.05)$.

Part 2- $\mathrm{KOH}$-soluble and insoluble fluoride on enamel

\section{Measurement of the enamel surface area}

The 60 enamel sample pairs ( $a$ and $b$ ) had their surface area measured using the computer software IM500 (Leica Microsystem AG, Milan, Italy). The mean $( \pm$ SD) surface area of these enamel samples was $10.65( \pm 3.19) \mathrm{mm}^{2}$.

\section{Measurement of the remaining enamel layer}

To measure $\mathrm{KOH}$-insoluble fluoride, a layer of enamel was ground $(100 \mu \mathrm{m})$. In order to verify if dentine would not be exposed, the thickness of the remaining enamel layer (from the dentino-enamel junction to the ground surface) was measured. The mean enamel thickness was $0.69( \pm 0.4) \mathrm{mm}$.

\section{$\mathrm{KOH}$-soluble and insoluble fluoride measurements}

Previously, the 60 enamel surfaces had been cut in half to obtain two enamel samples "a" and "b" from the same buccal surface. The 60 pairs of samples ("a" and "b") were randomly divided into four experimental groups ( $n=15$ pairs), and samples " $a$ " received a layer of varnish, while samples " $b$ " served as control (no fluoride exposure). Then, $0.025 \mathrm{~g}$ of the respective varnish $\left(\right.$ Duraphat $^{\circledR}$, Duofluorid ${ }^{\circledR}$, experimental varnish 1 or experimental varnish 2) was dispensed onto the ground enamel surface of samples "a". All samples $(a$ and $b)$ were individually placed in a $100 \%$ humidity chamber at $30^{\circ} \mathrm{C}$ for $4 \mathrm{~h}$. Later, the varnish was removed from the enamel surface using acetone and a scalpel blade, taking care not to touch the enamel surface, and then they were analyzed for $\mathrm{KOH}$-soluble fluoride [20] and $\mathrm{KOH}$-insoluble fluoride [21].

For $\mathrm{KOH}$-soluble fluoride, all enamel samples were individually immersed in potassium hydroxide $(24 \mathrm{~h}$ in $10 \mathrm{ml}$ $\mathrm{KOH} ; 1 \mathrm{M} ; 25^{\circ} \mathrm{C} ; 110 \mathrm{rpm} ; 25^{\circ} \mathrm{C}$ ) and placed in a vacuum chamber ( $7.0 \mathrm{kPa}$ pressure, equivalent to $93.1 \%$ vacuum) [20]. Afterwards, the samples were removed from the $\mathrm{KOH}$, and the solution was taken for fluoride analyses.

For $\mathrm{KOH}$-insoluble fluoride, each enamel sample was mounted on an abrading apparatus equipped with a micrometer [21]. The enamel was abraded using silicon carbide paper strips made from 1000 grit grinding paper. The silicon carbide paper was previously washed with perchloric acid $(8 \mathrm{~h}$; $0.0072 \mathrm{ml}$ of $3 \% \mathrm{HClO}_{4}$ per square millimeter of paper; $25{ }^{\circ} \mathrm{C}, 110 \mathrm{rpm}$ ) and dried overnight at $55^{\circ} \mathrm{C}$ before cutting into $90.0 \times 10.0$-mm strips. Each sandpaper strip was weighed using a precision balance $\left(1.0 \times 10^{-5} \mathrm{~g}\right.$; Sartorius Research, Instrumenten-Gesellschaft AG, Zürich, Switzerland) and used once to abrade a 50- $\mu \mathrm{m}$ layer of enamel. After abrading, the strip containing the enamel powder was weighed again, cut into small pieces, and placed into individual flasks. This procedure was repeated so that from each enamel sample, two $50-\mu \mathrm{m}$ layers were abraded: one from the outer layer and one from the inner layer. The difference between the weights of the sandpaper strip before and after the abrasion was used to calculate the weight of abraded enamel. Hydrochloric acid $\left(1 \mathrm{~mL}\right.$ of $\left.0.5 \mathrm{M} \mathrm{HCl} ; 25^{\circ} \mathrm{C}\right)$ was added to each flask containing the sandpaper strips and abraded enamel. The flasks were kept at $25{ }^{\circ} \mathrm{C}$ for $24 \mathrm{~h}$ under constant shaking (110 rpm; Stuart Mini Orbital Shaker). This acid was then analyzed for fluoride.

\section{Fluoride analyses}

Both $\mathrm{KOH}$-soluble and insoluble fluoride were analyzed using a fluoride electrode (PerfectION ${ }^{\mathrm{TM}}$; Mettler-Toledo, 
Schwerzenbach, Switzerland) connected to a voltmeter (SevenMulti; Mettler-Toledo).

For the $\mathrm{KOH}$-soluble fluoride, $100 \mu \mathrm{l}$ of the $\mathrm{KOH}$ solution was added to $900 \mu \mathrm{l}$ of a potassium acetate buffer. The detection limit of the fluoride electrode using this method was $0.2 \mathrm{ppm}$. The calibration of the electrode was carried out using fluoride standards prepared according to the reagents used (concentrations varying from 0.2 to $5.0 \mathrm{ppm}$ ). Each sample was measured in duplicate, and the concentration of $\mathrm{KOH}$-soluble fluoride was then calculated in $\mu \mathrm{g}$ of $\mathrm{F} / \mathrm{mm}^{2}$ of enamel.

For the analyses of the KOH-insoluble fluoride, $1 \mathrm{ml}$ of TISAB II buffer, containing $20 \mathrm{~g} / 1 \mathrm{NaOH}$, was added to the $\mathrm{HCl}$ samples [22]. The electrode was previously calibrated using fluoride standards with concentrations from 0.04 to $1.25 \mathrm{ppm}$ prepared according to the reagents in the samples. The fluoride samples were measured in duplicate, and the concentration of $\mathrm{KOH}$-insoluble fluoride was calculated in $m g$ of $\mathrm{F} / \mathrm{kg}$ of enamel.

\section{Statistical analyses}

Paired analyses were carried out for the experimental ( $a$ samples) and control ( $b$ samples) subgroups, as well as for the two enamel layers in each sample. As the data were not normally distributed, a Wilcoxon signed rank test was applied for each varnish group. Then, Kruskal-Wallis tests were used to analyze the differences between the varnish groups within the experimental subgroup, as well as with the respective control subgroup. Post hoc Wilcoxon rank sum tests were carried out between varnish group pairs. The significance levels were set at 0.05 with a Bonferroni-Holm adjustment for multiple testing.

Correlation analyses were also carried out considering all experimental groups with respect to the amount of $\mathrm{KOH}$ soluble fluoride versus the amount of $\mathrm{KOH}$-insoluble fluoride in the outer layer of enamel, as well as with respect to the amount of $\mathrm{KOH}$-insoluble fluoride in the outer versus inner layer of enamel.

All statistical analyses made in the present study were performed using the R Project for Statistical Computing (www.r-project.org; Vienna, Austria).

\section{Results}

For the cyclic erosion experiment, the median ( \pm median absolute deviation) surface hardness values are presented in
Table 1, and the difference in hardness between the different experimental stages are presented in Table 2.

In general, throughout the experiment, enamel surface hardness decreased to different degrees in the different groups, as shown by the significant differences between the varnishes $(p<0.001)$ and between the time points $(p<0.001)$. Also, the interaction between time and group intensified this $\mathrm{SMH}$ decrease $(p<0.001)$.

After the first erosion cycle, there was no significant difference between the groups $(p=0.107)$, demonstrating a similar initial decrease in enamel hardness for all groups. A significant difference between the groups was observed after varnish application $(p<0.001)$. Also, the difference between $\mathrm{SMH}_{\mathrm{C}}$ and $\mathrm{SMH}_{\mathrm{E}}$ (after varnish application and the third erosion cycle) showed that all fluoride varnishes caused a significantly lower hardness decrease than the control and base varnish group. On the other hand, analyzing the total hardness loss observed throughout the whole experiment (difference between $\mathrm{SMH}_{\mathrm{A}}$ and $\mathrm{SMH}_{\mathrm{E}}$ ), only Duraphat ${ }^{\mathbb{R}}$ showed a protective effect against enamel softening compared to the control and the base varnish groups $(p<0.001)$. Whereas, Duofluorid $^{\circledR}$, experimental varnish 1 , and experimental varnish 2 obtained statistically similar hardness loss to Duraphat ${ }^{\circledR}$, base varnish, and the control group. Figure 1a-f shows the typical honeycomb pattern of erosive demineralization of the enamel. This enamel demineralization pattern was present in samples from all groups, but specimens of the group treated with Duraphat ${ }^{\circledR}$ also presented varnish reminiscent on the enamel surface (Fig. 1b).

In the $\mathrm{KOH}$-soluble fluoride analysis, the samples in the control subgroup (not exposed to the varnishes) had values below the detectable limit, but samples in the experimental subgroups had significantly higher fluoride levels, except for the experimental varnish 1 , which showed similar values to the control group. The samples exposed to Duraphat ${ }^{\circledR}$ and to the experimental varnish 2 had lower $\mathrm{KOH}$-soluble fluoride than those exposed to Duofluorid ${ }^{\circledR}$ and the experimental varnish 1 (Table 3).

Overall, the samples in the experimental subgroups had significantly greater amounts of $\mathrm{KOH}$-insoluble fluoride than those in the control subgroups, except for the inner enamel layer of the samples exposed to Duraphat ${ }^{\circledR}$. These samples showed similar amounts of fluoride between the experimental and control subgroups ( $p=0.118$ ) (Table 3 ).

Since the samples of the control groups were not exposed to varnishes, their pooled values were used to calculate the mean base fluoride values for the teeth used in this experiment. The mean ( \pm standard deviation) base values of $\mathrm{KOH}-$ insoluble fluoride for the outer and inner layers of enamel were $134.1( \pm 87.0)$ and $105.0( \pm 66.3) \mathrm{mg} \mathrm{F} / \mathrm{kg}$ enamel, respectively $(p<0.01)$.

A weak correlation was seen between the $\mathrm{KOH}$-soluble fluoride and the $\mathrm{KOH}$-insoluble fluoride in the outer layer of 
Table 1 Median ( \pm median absolute deviation) of enamel surface hardness at different experimental stages of the experiment $\left(\mathrm{SMH}_{\mathrm{A}}\right.$ to $\left.\mathrm{SMH}_{\mathrm{E}}\right)$

\begin{tabular}{|c|c|c|c|c|c|}
\hline \multirow[t]{2}{*}{ Group } & \multicolumn{5}{|c|}{ Experimental stage } \\
\hline & $\begin{array}{l}\mathrm{SMH}_{\mathrm{A}} \\
\text { Initial }\end{array}$ & $\begin{array}{l}\mathrm{SMH}_{\mathrm{B}} \\
\text { After first } \\
\text { erosion cycle }\end{array}$ & $\begin{array}{l}\mathrm{SMH}_{\mathrm{C}} \\
\text { After } 4 \mathrm{~h} \\
\text { of varnish }\end{array}$ & $\begin{array}{l}\mathrm{SMH}_{\mathrm{D}} \\
\text { After second } \\
\text { erosion cycle }\end{array}$ & $\begin{array}{l}\mathrm{SMH}_{\mathrm{E}} \\
\text { Final }\end{array}$ \\
\hline Base varnish & $356.2( \pm 5.3)$ & $313.3( \pm 5.8)$ & $308.3( \pm 8.2)$ & $275.0( \pm 8.9)$ & $250.4( \pm 12.8)$ \\
\hline Duraphat ${ }^{\circledR}$ & $357.6( \pm 4.7)$ & $314.4( \pm 11.8)$ & $311.7( \pm 19.2)$ & $278.3( \pm 14.6)$ & $271.8( \pm 9.5)$ \\
\hline Duofluorid ${ }^{\circledR}$ & $351.1( \pm 8.5)$ & $313.9( \pm 8.7)$ & $299.0( \pm 11.7)$ & $272.2( \pm 8.5)$ & $255.9( \pm 13.3)$ \\
\hline Experimental varnish 1 & $354.8( \pm 8.1)$ & $317.0( \pm 5.0)$ & $280.0( \pm 9.4)$ & $263.3( \pm 11.6)$ & $268.7( \pm 9.5)$ \\
\hline Experimental varnish 2 & $359.6( \pm 5.6)$ & $317.5( \pm 6.2)$ & $284.9( \pm 14.6)$ & $268.7( \pm 13.3)$ & $270.9( \pm 8.6)$ \\
\hline No varnish & $346.3( \pm 9.5)$ & $310.5( \pm 6.8)$ & $313.1( \pm 9.8)$ & $274.3( \pm 10.3)$ & $244.4( \pm 11.8)$ \\
\hline
\end{tabular}

enamel $\left(r^{2}=0.35\right)$. However, there was a medium correlation between the amount of $\mathrm{KOH}$-insoluble fluoride in the outer and inner layers of enamel $\left(r^{2}=0.56\right)$.

\section{Discussion}

Previous studies have shown that fluoride varnishes can protect enamel against dental erosion, especially when experimental models with more severe erosion are used [5, 23, 24]. In the present study, we used milder erosive challenges [25] in an effort to understand the behavior of the varnishes in a very initial erosion model. The steady decrease in surface microhardness in all groups shows that fluoride varnishes do not prevent erosive wear completely [5], but erosion progression was significantly hindered by Duraphat ${ }^{\circledR}$.

It is generally accepted that the protective effect of fluoride varnishes towards dental erosion is related to the formation of a layer of $\mathrm{CaF}_{2}$-like material on enamel [26]. This layer will readily dissolve in acid, but it serves as an additional physical barrier hindering the dissolution of the underlying enamel mineral $[27,26]$. In fact, the application of all fluoride varnishes caused an increase in $\mathrm{KOH}$-soluble and insoluble fluoride on enamel $[28,29]$; therefore, a protective effect was expected against erosion.

Initially, no $\mathrm{KOH}$-soluble fluoride was found on the surface of the control group. This was already expected because the enamel was ground and polished to obtain a flat smooth surface. The initial analyses on the control group were carried out on this nude enamel surface, which had no previous fluoride treatment. However, on the experimental group, the application of fluoride varnishes indeed caused an increase in $\mathrm{KOH}$-soluble fluoride, but this did not increase the surface microhardness of the enamel after the initial erosive challenge. In that case, it may be suggested that after a 4-h period of fluoride varnish application, no measurable remineralization occurred. On the other hand, the fluoride layer formed after the varnish application was expected to protect enamel from erosive demineralization, but the varnishes that formed greater amounts of fluoride on enamel (Duofluorid ${ }^{\circledR}$ and experimental varnish 1) behaved in a similar manner to the base varnish (no fluoride), although Duraphat ${ }^{\circledR}$ formed lower amounts of fluoride on enamel and presented significantly greater enamel protection. From these observations, it may be speculated that

Table 2 Median ( \pm median absolute deviation) of the difference in enamel surface hardness $\left(\Delta \mathrm{SMH}_{\mathrm{i}}\right)$ from two experimental stages

\begin{tabular}{|c|c|c|c|c|c|}
\hline \multirow[t]{2}{*}{ Group } & \multicolumn{5}{|c|}{ Difference between two experimental stages } \\
\hline & $\begin{array}{l}\mathrm{SMH}_{\mathrm{A}}-\mathrm{SMH}_{\mathrm{B}} \\
\text { Initial and after first } \\
\text { erosion cycle }\end{array}$ & $\begin{array}{l}\mathrm{SMH}_{\mathrm{B}}-\mathrm{SMH}_{\mathrm{C}} \\
\text { After first erosion } \\
\text { cycle and after } 4 \mathrm{~h} \\
\text { of varnish }\end{array}$ & $\begin{array}{l}\mathrm{SMH}_{\mathrm{A}}-\mathrm{SMH}_{\mathrm{C}} \\
\text { Initial and after } 4 \mathrm{~h} \\
\text { of varnish }\end{array}$ & $\begin{array}{l}\mathrm{SMH}_{\mathrm{C}}-\mathrm{SMH}_{\mathrm{E}} \\
\text { After } 4 \mathrm{~h} \text { of } \\
\text { varnish and after } \\
\text { third erosion cycle }\end{array}$ & $\begin{array}{l}\mathrm{SMH}_{\mathrm{A}}-\mathrm{SMH}_{\mathrm{E}} \\
\text { Initial and after third } \\
\text { erosion cycle }\end{array}$ \\
\hline Base varnish & $-43.3( \pm 2.3) \mathrm{A}$ & $-0.5( \pm 7.6) \mathrm{A}$ & $-46.3( \pm 12.4) \mathrm{A}, \mathrm{B}$ & $-55.0( \pm 7.2) \mathrm{A}$ & $-101.4( \pm 17.0) \mathrm{A}$ \\
\hline Duraphat $^{\mathbb{R}}$ & $-41.1( \pm 5.3) \mathrm{A}$ & $-8.3( \pm 16.0) \mathrm{A}$ & $-50.5( \pm 13.3) \mathrm{A}, \mathrm{B}$ & $-21.1( \pm 17.9) \mathrm{B}$ & $-75.2( \pm 17.1) \mathrm{B}$ \\
\hline Duofluorid ${ }^{\circledR}$ & $-40.4( \pm 8.2) \mathrm{A}$ & $-14.0( \pm 16.2) \mathrm{A}, \mathrm{B}$ & $-53.0( \pm 13.3) \mathrm{A}, \mathrm{C}$ & $-25.2( \pm 17.9) \mathrm{B}$ & $-95.6( \pm 17.1) \mathrm{A}, \mathrm{B}$ \\
\hline Experimental varnish 1 & $-34.5( \pm 8.6) \mathrm{A}$ & $-29.2( \pm 14.7) \mathrm{B}$ & $-65.0( \pm 12.2) \mathrm{B}, \mathrm{C}$ & $-21.6( \pm 7.2) \mathrm{B}$ & $-84.0( \pm 17.8) \mathrm{A}, \mathrm{B}$ \\
\hline Experimental varnish 2 & $-41.9( \pm 5.0) \mathrm{A}$ & $-28.2( \pm 16.4) \mathrm{B}$ & $-82.1( \pm 12.2) \mathrm{C}$ & $-15.7( \pm 21.6) \mathrm{B}$ & $-93.6( \pm 18.1) \mathrm{A}, \mathrm{B}$ \\
\hline No varnish & $-35.5( \pm 5.5) \mathrm{A}$ & $+3.8( \pm 10.4) \mathrm{A}$ & $-31.7( \pm 6.8) \mathrm{A}$ & $-69.6( \pm 8.2) \mathrm{A}$ & $-103.8( \pm 10.5) \mathrm{A}$ \\
\hline
\end{tabular}

Same letters means no significant differences between the varnishes within same column 

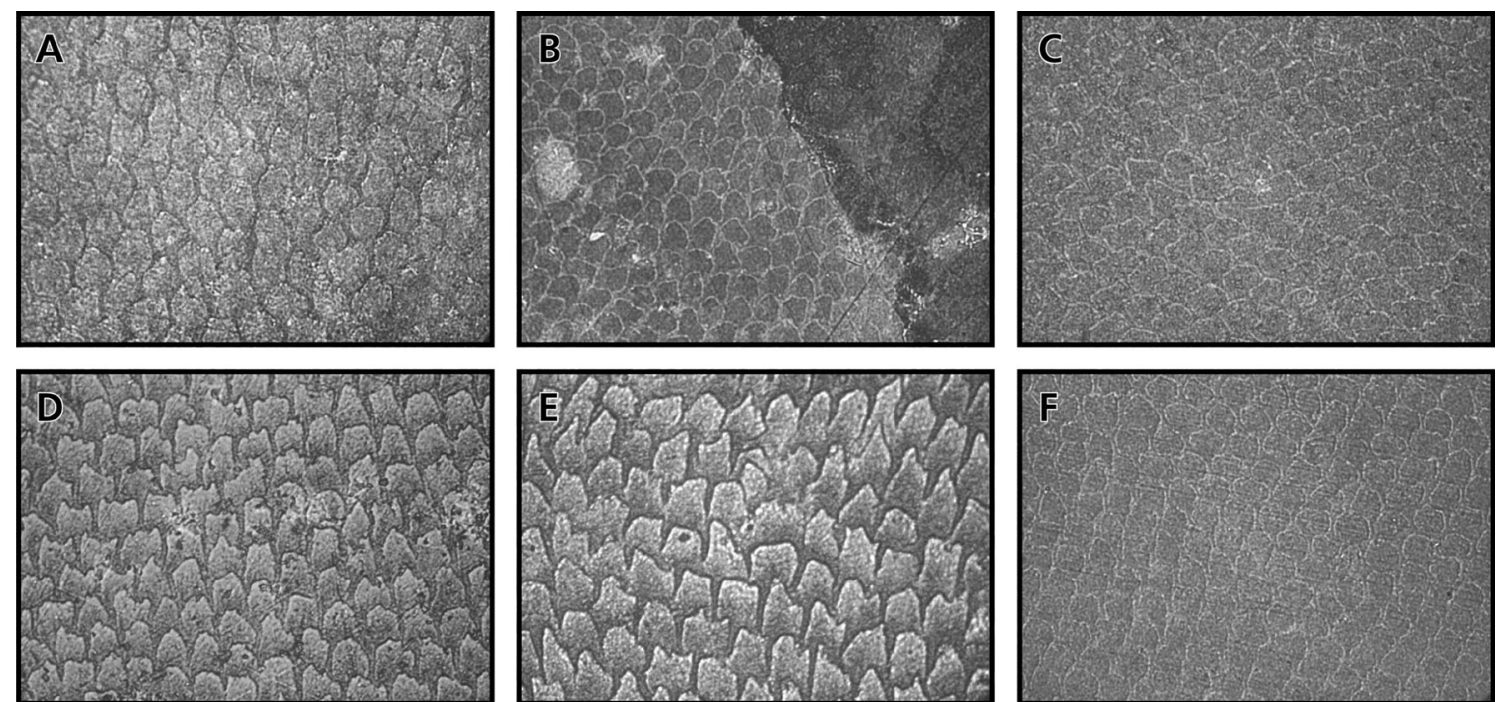

Fig. 1 Optical micrographs ( $\times 50$ magnification $)$ of the enamel surfaces of specimens treated with the following: a base varnish; b Duraphat ${ }^{\mathbb{R}} ; \mathbf{c}$ Duofluorid $^{\mathbb{R}}$; d experimental varnish 1 ; e experimental varnish 2 ; f control group with no varnish. Note all specimens present the typical

honeycomb pattern of erosive demineralization, but the specimens covered with Duraphat ${ }^{\mathbb{B}}$ present areas of varnish reminiscent (dark area in Fig. 1b)

the fluoride layer probably does not play a major role on the protection against erosion.

The protective effect observed with Duraphat ${ }^{\circledR}$ in relation to the control group could then be either due to a slightly lower $\mathrm{pH}$ or to the different resin components present in the body of the varnish. On the one hand, fluoride vehicles with acidic $\mathrm{pH}$ can form greater amounts of $\mathrm{KOH}$-soluble fluoride on enamel [8], but the $\mathrm{pH}$ of Duraphat ${ }^{\mathbb{B}}(\mathrm{pH}=6.02)$ was close to neutral, and it did not promote significantly greater fluoride concentration on enamel. On the other hand, Duraphat ${ }^{\circledR}$ contains different resins, and traces of the varnish can remain adhered to the enamel surface after its application (Fig. 1b). This resin reminiscent will promote a mechanical barrier for the enamel $[24,5]$. This was the main reason for using the base varnish, with no active ingredients. The base varnish was a positive control for Duofluorid ${ }^{\circledR}$ and for both experimental varnishes. When the base varnish was applied to enamel, the surface microhardness loss in this group was similar to that of

Table 3 Median ( \pm median absolute deviation) of the amount of $\mathrm{KOH}$-soluble $\left[\mathrm{mg} \mathrm{F} / \mathrm{mm}^{2}\right]$ and insoluble $[\mathrm{mg} \mathrm{F} / \mathrm{kg}$ enamel $]$ fluoride, according to the enamel layer, in samples exposed or not to the test varnishes

\begin{tabular}{|c|c|c|c|c|}
\hline \multirow[t]{2}{*}{ Enamel layer } & & \multirow[t]{2}{*}{ Varnish } & \multicolumn{2}{|l|}{ Enamel sample group } \\
\hline & & & Varnish & Control \\
\hline \multirow{4}{*}{$\begin{array}{l}\mathrm{KOH} \text {-soluble fluoride } \\
\qquad(\mathrm{mg} \mathrm{F} / \mathrm{mm} 2)\end{array}$} & \multirow[t]{4}{*}{ Surface } & Duraphat $^{\circledR}$ & $0.311( \pm 0.30) \mathrm{A}, \mathrm{a}$ & $0 \mathrm{~b}$ \\
\hline & & Duofluorid ${ }^{\circledR}$ & $0.540( \pm 0.19) \mathrm{B}, \mathrm{a}$ & $0 \mathrm{~b}$ \\
\hline & & Experimental varnish 1 & $0.703( \pm 0.23) \mathrm{B}, \mathrm{a}$ & $0 \mathrm{a}$ \\
\hline & & Experimental varnish 2 & $0.363( \pm 0.06) \mathrm{A}, \mathrm{a}$ & $0 \mathrm{~b}$ \\
\hline \multirow{8}{*}{$\begin{array}{l}\text { KOH-insoluble fluoride } \\
\text { (mg F/kg enamel) }\end{array}$} & \multirow[t]{4}{*}{ Outer enamel } & Duraphat ${ }^{\circledR}$ & $256.3( \pm 151.9) \mathrm{A}, \mathrm{B}, \mathrm{a}$ & $93.4( \pm 20.9) b$ \\
\hline & & Duofluorid ${ }^{\circledR}$ & $560.6( \pm 226.0) \mathrm{C}, \mathrm{a}$ & $125.4( \pm 54.5) \mathrm{b}$ \\
\hline & & Experimental varnish 1 & $553.8( \pm 163.7) \mathrm{B}, \mathrm{C}, \mathrm{a}$ & $122.8( \pm 37.4) \mathrm{b}$ \\
\hline & & Experimental varnish 2 & $208.0( \pm 64.1) \mathrm{A}, \mathrm{a}$ & $90.2( \pm 17.6) \mathrm{b}$ \\
\hline & \multirow[t]{4}{*}{ Inner enamel } & Duraphat $^{\circledR}$ & $104.8( \pm 43.9) \mathrm{A}, \mathrm{a}$ & $67.9( \pm 26.1) \mathrm{a}$ \\
\hline & & Duofluorid ${ }^{\circledR}$ & $277.4( \pm 107.3) B, a$ & $88.5( \pm 26.8) b$ \\
\hline & & Experimental varnish 1 & $276.1( \pm 100.7) \mathrm{B}, \mathrm{a}$ & $108.3( \pm 35.5) \mathrm{b}$ \\
\hline & & Experimental varnish 2 & $100.9( \pm 24.4) \mathrm{A}, \mathrm{a}$ & $79.1( \pm 7.1) \mathrm{b}$ \\
\hline
\end{tabular}

Same letters means no significant differences between the groups (difference between varnishes in columns: uppercase letters [A]; difference between varnish and control groups in rows: lowercase letters [a]) within the same enamel layer (surface, outer enamel, inner enamel). Values below the detection limit were considered as 0 on this table 
the negative control (no varnish) group. This suggests that no mechanical protection was observed with the base varnish (Fig. 1a). So it may be concluded that the Duofluorid ${ }^{\circledR}$ (Fig. 1c) and the CaGP varnishes (Fig. 1d, e) also caused no mechanical protection on the enamel. Nonetheless, though the use of the base varnish allows us to come to such a conclusion for Duofluorid ${ }^{\circledR}$ and the experimental varnishes 1 and 2, we unfortunately cannot come to the same conclusion in relation to Duraphat ${ }^{\mathbb{R}}$. This is because Duraphat ${ }^{\circledR}$ is made up of different resins than those used in the base varnish, and its "protective" effect could in fact be due to the mechanical action of varnish reminiscent observed on the enamel surface (Fig. 1b). However, the lack of availability of a fluoride-free varnish formulation similar to Duraphat ${ }^{\circledR}$ hinders any further analysis on the actual impact of these resins in "protecting" against dental erosion.

It has been previously stated that CaGP can interact with the dental enamel [15]. Also, previous experiments (results not shown) showed that the CaGP-containing varnishes released significantly more fluoride than the other varnishes. So, it could be speculated that the varnishes containing CaGP would promote a greater formation of $\mathrm{KOH}$-soluble fluoride increasing the protection of enamel against erosion. However, fluoride concentration on enamel after application of the CaGP-containing varnishes was either similar (for experimental varnish 1) or lower (for experimental varnish 2) than the positive control (Duofluorid ${ }^{\circledR}$ ). Consequently, the addition of CaGP to fluoride varnish did not increase the amount of $\mathrm{KOH}$-soluble and insoluble fluoride on enamel, which possibly accounts for the lack of significance in its protection against erosion.

When tracing a parallel between both parts of the studypresence of fluoride after varnish application and the protection against erosion - one must bear in mind that both parts of the experiment were carried out on different depths of enamel, as different enamel depths have different enamel components [30], and they could react differently to fluoride and erosive challenges. Nonetheless, in conclusion, the addition of CaGP to fluoride varnishes did not increase the amount of fluoride loosely and firmly bound to enamel, and it did not increase enamel protection against erosive demineralization.

\begin{abstract}
Acknowledgments The authors are very grateful for Barbara Beyeler's persistence and determined efforts during the laboratory procedures. We thank Dr. S. Hayoz and Prof. J. Hüsler, Institute of Mathematical Statistics and Actuarial Science, University of Bern, for performing the statistical analyses. We greatly appreciate the valuable comments from the participants of the Post-Graduation in Pediatric Dentistry (FOUSP). Finally, we thank FGM, Brazil, for their support in manufacturing the varnishes and the financial support from Conselho Nacional de Desenvolvimento Científico e Tecnológico (CNPq, www.cnpq.br; grant number 201901/ 2009-9).
\end{abstract}

Conflict of interest The authors declare that they have no conflict of interest.

\section{References}

1. Lussi A, Megert B, Eggenberger D, Jaeggi T (2008) Impact of different toothpastes on the prevention of erosion. Caries Res 42(1): 62-67

2. Ganss C, Lussi A, Grunau O, Klimek J, Schlueter N (2011) Conventional and anti-erosion fluoride toothpastes: effect on enamel erosion and erosion-abrasion. Caries Res 45(6):581-589. doi:10. $1159 / 000334318$

3. Sales-Peres S, Pessan J, Buzalaf M (2007) Effect of an iron mouthrinse on enamel and dentine erosion subjected or not to abrasion: an in situ/ex vivo study. Arch Oral Biol 52(2):128-132. doi:10. 1016/j.archoralbio.2006.08.010

4. Ganss C, Klimek J, Brune V, Schürmann A (2004) Effects of two fluoridation measures on erosion progression in human enamel and dentine in situ. Caries Res 38(6):561-566. doi:10.1159/000080587

5. Murakami C, Bönecker M, Corrêa M, Mendes F, Rodrigues C (2009) Effect of fluoride varnish and gel on dental erosion in primary and permanent teeth. Arch Oral Biol 54(11):997-1001. doi:10.1016/j. archoralbio.2009.08.003

6. Petersson L (1975) On topical application of fluorides and its inhibiting effect on caries. Odontol Revy Suppl 34:1-36

7. Ogaard B, Rölla G, Helgeland K (1984) Fluoride retention in sound and demineralized enamel in vivo after treatment with a fluoride varnish (Duraphat). Scand J Dent Res 92(3):190-197

8. Saxegaard E, Rölla G (1988) Fluoride acquisition on and in human enamel during topical application in vitro. Scand J Dent Res 96(6): $523-535$

9. Hughes J, West N, Addy M (2004) The protective effect of fluoride treatments against enamel erosion in vitro. J Oral Rehabil 31(4):357363. doi:10.1046/j.1365-2842.2003.01240.x

10. Ganss C, Schlueter N, Klimek J (2007) Retention of KOH-soluble fluoride on enamel and dentine under erosive conditions-a comparison of in vitro and in situ results. Arch Oral Biol 52(1):9-14. doi:10. 1016/j.archoralbio.2006.07.004

11. Grenby T (1973) Trials of 3 organic phosphorus-containing compounds as protective agents against dental caries in rats. J Dent Res 52(3):454-461

12. Pianotti R, Ambrozaitis J, McNamara T (1976) Cariostatic activity of calcium glycerophosphate in hamsters: topical vs dietary administration. J Dent Res 55(6):1092-1096

13. Mainwaring P, Naylor M (1983) A four-year clinical study to determine the caries-inhibiting effect of calcium glycerophosphate and sodium fluoride in calcium carbonate base dentifrices containing sodium monofluorophosphate. Caries Res 17(3):267-276

14. Grenby TH, Bull JM (1980) Use of high-performance liquid chromatography techniques to study the protection of hydroxylapatite by fluoride and glycerophosphate against demineralization in vitro. Caries Res 14(4):221-232

15. Grenby TH, Bull JM (1980) Chemical studies of the protective action of phosphate compounds against the demineralization of human dental enamel in vitro. Caries Res 14(4):210-220

16. Carvalho TS, Peters BG, Rios D, Magalhães AC, Sampaio FC, Buzalaf MAR, Bönecker M Fluoride varnishes with calcium glycerophosphate: Fluoride release and effect on in vitro enamel demineralization. Submitted to brazilian oral research

17. Buck R, Rondinini S, Covington A, Baucke F, Brett C, Camões M, Milton M, Mussini T, Naumann R, Pratt K, Spitzer P, Wilson G (2002) Measurement of $\mathrm{pH}$. Definition, standards, and procedures. IUPAC recommendations 2002. Pure Appl Chem 74(11):2169-2200

18. Newby C, Creeth J, Rees G, Schemehorn B (2006) Surface microhardness changes, enamel fluoride uptake, and fluoride availability from commercial toothpastes. J Clin Dent 17(4):94-99

19. Brunner E, Domhof S, Langer F (2002) Nonparametric analysis of longitudinal data in factorial experiments, 1 st edn. Wiley, New York 
20. Caslavska V, Moreno E, Brudevold F (1975) Determination of the calcium fluoride formed from in vitro exposure of human enamel to fluoride solutions. Arch Oral Biol 20(5-6):333-339

21. Altenburger M, Schirrmeister J, Lussi A, Klasser M, Hellwig E (2009) In situ fluoride retention and remineralization of incipient carious lesions after the application of different concentrations of fluoride. Eur J Oral Sci 117(1):58-63

22. Cury J, do Amaral R, Tenuta L, Del Bel Cury A, Tabchoury C (2010) Low-fluoride toothpaste and deciduous enamel demineralization under biofilm accumulation and sucrose exposure. Eur J Oral Sci 118(4):370-375. doi:10.1111/j.1600-0722.2010.00745.x

23. Magalhães A, Kato M, Rios D, Wiegand A, Attin T, Buzalaf M (2008) The effect of an experimental $4 \%$ Tif4 varnish compared to $\mathrm{NaF}$ varnishes and $4 \% \mathrm{TiF} 4$ solution on dental erosion in vitro. Caries Res 42(4):269-274. doi:10.1159/000135672

24. Vieira A, Jager D, Ruben J, Huysmans M (2007) Inhibition of erosive wear by fluoride varnish. Caries Res 41(1):61-67
25. Voronets J, Lussi A (2010) Thickness of softened human enamel removed by toothbrush abrasion: an in vitro study. Clin Oral Investig 14(3):251-256. doi:10.1007/s00784-009-0288-y

26. Magalhães AC, Wiegand A, Rios D, Buzalaf MA, Lussi A (2011) Fluoride in dental erosion. Monogr Oral Sci 22:158-170. doi:10. $1159 / 000325167$

27. Ganss C, Klimek J, Schäffer U, Spall T (2001) Effectiveness of two fluoridation measures on erosion progression in human enamel and dentine in vitro. Caries Res 35(5):325-330

28. Attin T, Grieme R, Paqué F, Hannig C, Buchalla W, Attin R (2005) Enamel fluoride uptake of a novel water-based fluoride varnish. Arch Oral Biol 50(3):317-322

29. Hellwig E, Klimek J, Schmidt HF, Egerer R (1985) Fluoride uptake in plaque-covered enamel after treatment with the fluoride lacquer Duraphat. J Dent Res 64(8):1080-1083

30. Weatherell JA, Robinson C, Hallsworth AS (1974) Variations in the chemical composition of human enamel. J Dent Res 53(2):180-192 